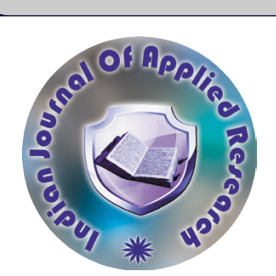

Anaesthesiology

\title{
A CASE REPORT- A CASE OF RIGHT SIDED ABSENT MAXILLA WITH ANTICIPATED DIFFICULT AIRWAY POSTED FOR PERINEAL URETHROPLATY
}

\section{Dr. Tanya Elizabeth Cherian*}

Junior resident, Department of Anaesthesiology and Critical Care, Sree Balaji Medical college and hospital, Chennai. ${ }^{*}$ Corresponding Author

\section{Dr. M. Sathyasuba}

Assistant Professor, Department of Anaesthesiology and Critical Care, Sree Balaji Medical college and hospital, Chennai.

ABSTRACT The key to success in patients with difficult airway is effective airway assessment and meticulous planning. Making use of simple and time-tested equipment and modifying these methods accordingly enable successful airway control avoiding perioperative morbidity and mortality. We report a case of 75 year old male with posterior urethral stricture planned for perineal urethroplasty with anticipated difficult airway. The airway was managed using video laryngoscopy and the procedure was uneventful with good postoperative recovery. This case report insists on making use of other conventional methods in the effective management of an anticipated difficult airway during a pandemic.

KEYWORDS : Difficult airway, conventional, anticipated, airway management

\section{INTRODUCTION}

Airway management is the primary skill that all airway managers (anaesthesiologists, intensivists, emergency physicians) needs to master. ${ }^{1}$ The ultimate goal of the management of a difficult airway is to avert the patient's oxygenation or hemodynamic status from worsening to dangerous levels. ${ }^{2,3}$ Never before have had these challenges acquired a gigantic stature as they have during the present corona pandemic. The basis of managing a difficult airway is to maintain spontaneous ventilation by using either intravenous inducing agents in titrated doses or inhalational agents until the airway is secured ${ }^{4}$. The aim is to deepen the plane of anesthesia sufficiently to perform direct laryngoscopy, but it is important to minimize the repeated attempts to prevent airway trauma. If conventional techniques fail, one must have an alternate plan or should wake up the patient or proceed with surgical airway. ${ }^{5,6}$

This pandemic is necessitating and forcing the anaesthesia fraternity to bring some changes to the established definite algorithm of difficult airway management. ${ }^{10}$

\section{CASE REPORT}

A 75 year old male patient was diagnosed with posterior urethral stricture and was planned for perineal urethroplasty. He was a known diabetic for 10 years on oral hypoglycemic agents, known hypertensive and chronic kidney disease on regular medication and not on dialysis. Patient had undergone right sided maxillectomy for a benign tumour of the maxilla 8 years ago. Airway examination revealed mallampati grade iii with facial asymmetry, edentulous, being elderly contributing to difficult mask ventilation with mouth opening admitting 2 and half fingers and normal range of neck movements. Patient had age related kyphoscoliosis. Investigations revealed hemoglobin of $10.9 \mathrm{gms}$, with random blood sugar of 404 $\mathrm{mg} / \mathrm{dl}$, hbalc of 7 , urea of 80 , creatinine $3 \mathrm{mg} / \mathrm{dl}$ and inr of 1.7 . cardiologists and nephrologists opinion(advised hemodialysis if needed) was sought and fitness was given under ASA III. Preoperative covid testing was done and the patient was negative for it.

On the day of surgery the operating room checking with anesthesia machine checking was done. Difficult airway cart was kept ready. This included masks of different sizes, oropharyngeal airway and nasopharyngeal airways of various sizes, intubating stylet, bougie , different sizes of endotracheal tubes (size 6.5, 7.0, 7.5, 8.0), LMAs, laryngoscopes with curved blades, equipment for surgical airway such as cricothyroidotomy and tracheostomy kits and large bore suction catheters. Personel protective equipment was worn by all the operating room personnels as per instituitional protocol. After ensuring the nil per oral status, the patient was shifted to the operating room and iv line was secured. Procedure was planned to be done under general anesthesia because of the deranged coagulation status and kyphoscoliosis even though regional anesthesia is the preferred technique of choice during this pandemic. Even though fiberoptic bronchoscopy is the gold standard procedure for difficult airway it is a highly aerosol generating procedure and is currently avoided. In this pandemic. Patient was preoxygenated for 5 mins with $100 \%$ oxygen induced with Inj thiopentone and plane was deepened with sevoflurane to avoid coughing and aerosol generation and king vision video laryngoscopy was performed and was Cormack lehane grade II and patient was intubated with 7.0 size endotracheal tube after clamping the tube, the circuit was connected and the tube clamp was released, bilateral air entry was checked and the tube was fixed at $21 \mathrm{~cm}$. T Two high quality HME filter one between the tracheal tube and the breathing circuit and the second between expiratory limb and anesthesia machine. Depth of anesthesia maintained with oxygen, nitrous oxide, sevoflurane and atracurium. Oxygen Saturation, heart rate, gas monitoring, end tidal carbon dioxide and NIBP was monitored throughout the procedure. Closed suction system was used for suctioning during emergence. The patient was reversed and extubated and recovery was uneventful.

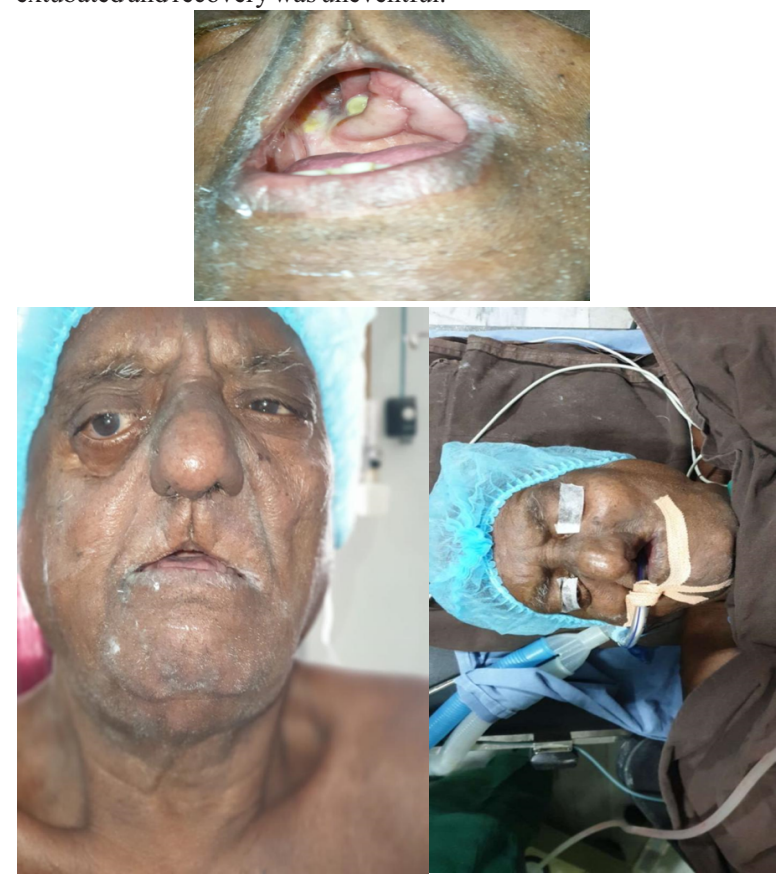

\section{DISCUSSION}

The presence of a difficult airway is a significant patient related risk factor associated with increased perioperative morbidity and mortality. ${ }^{7}$ The anaesthesiologists should have other options for airway control and it should be discussed well in advance with the other team members. ${ }^{4}$ Although fiberoptic intubation is the gold standard for the management of difficult airway, it has its own limitations. Although some changes, techniques and equipment have been described to prevent the transmission of infection during intubation and other anaesthesia procedures, they can all the more increase the incidence of difficulty in securing a difficult airway, as anaesthesiologists have not 
been accustomed completely with newer preventive equipment. ${ }^{10}$ Some examples of such equipment designed for intubation are the aerosol box (intubation/extubation box), plastic sheets and face shields. The guidelines say that to increase the success of intubation in the first attempt, it is important that the most experienced airway operator deals with the airway management as there is a high chance that intubation in COVID cases can become cumbersome as described above. Communication issues wearing PPE are common and are to be discussed with the OR personnel. In the absence of fiberoptic bronchoscope and other advanced and alternate methods can be used to secure the airway. Success of such techniques depend on consistent maintenance of an unobstructed airway and an adequate depth of anaesthesia. ${ }^{8}$ Direct laryngoscopy can be an efficient and alternative method in difficult airway situations because it may be possible to bring the larynx into view ${ }^{9} \mathrm{~A}$ video laryngoscope (VL) is now adviced to be used if available for intubation success and to increase the distance between the patient's airway and the intubator's airway during the first attempt and the next two attempts in case of failure to intubate during the first attempt. ${ }^{11,12}$ The type of VL to be used and training in its use are important as all anaesthesiologists may not be familiar with their use. A disposable VL or a VL with a disposable blade is recommended $^{13}$. A VL with a separate screen to enable the airway operator to stay away from the airway is useful. ${ }^{14}$

However, the anaesthesiologist should have an alternative plan such as cricothyroidotomy or tracheostomy to secure the airway in such situations.

Our patient has multiple co morbidities, such as diabetes( which itself can be a cause of difficult airway), hypertension and chronic kidney disease. Age related system wise changes are also to be kept in mind and meticulously managed. It is important to remember the fundamental principles of airway management - oxygenation, not intubation, is life-saving.

\section{CONCLUSION}

Choosing an appropriate technique for management of both anticipated and unanticipated difficult airway should be executed wisely and precisely with ideal airway devices. Thorough knowledge and skill in all the techniques should be mastered as mismanaged difficult airways can lead to disastrous consequences.

\section{CONFLICT OF INTEREST : NONE}

\section{REFERENCES}

1. Umesh G. Difficult airway: Challenges, phobias and options. Indian J Anaesth 2017;61:611-3

2. Pearce A. Evaluation of the airway and preparation for difficulty. Best practice and research clinical anesthesiology 2005; 19:559-79

3. Isono S, Ishikawa T. Oxygenation, not intubation, does matter. Anesthesiology 2011;114:7-9.

4. Upadhya KR, Ramavakoda CY, Ravindra M, Ganigara A. Management of predicted difficult airway with conventional techniques in an infant with rhabdomyosarcoma of the upper lip. Indian J Anaesth 2017;61:508-10

5. Walker RW, Ellwood J. The management of difficult intubation in children. Paediatr Anaesth 2009;19 Suppl 1:77-87

6. Pawar DK, Doctor JR, Raveendra US, Ramesh S, Shetty SR, Divatia JV, et al. All India Difficult Airway Association 2016 guidelines for the management of unanticipated difficult tracheal intubation in Paediatrics. Indian J Anaesth. 2016;60:906-14.

7. Huang AS, Hajduk J, Rim C, Coffield S, Jagannathan N. Focused review on management of the difficult paediatric airway. Indian J Anaesth. 2019;63(6):428-436. doi:10.4103/ija.IJA_250_19

8. Kundra P, Krishnan $\bar{H}$. Airway management in children. Indian J Anaesth 2005;49:300-7.

9. Guimaraes J, Frada R, Leal T, Orfao JM, Machado HS. Careful planning in a pediatric Guimaraes J, Frada R, Leal T, Orfao JM, Machado HS. Careful planning in a pediatric
expected difficult airway in a specialized tertiary hospital: What can go wrong? A case report. JAnesth Clin Res 2015;6:563.

10. Bajwa SJ, Kurdi M, Stroumpoulis K. Difficult airway management in COVID times. Indian J Anaesth 2020;64, Suppl S2:116-9

11. Malhotra N, Joshi M, Datta R, Bajwa SJ, Mehdiratta L. Indian society of anaesthesiologists (ISA National) advisory and position statement regarding COVID19. Indian JAnaesth 2020;64:259-63.

12. Malhotra N, Bajwa SJ, Joshi M, Mehdiratta L, Trikha A. COVID Operation Theatre. Advisory and Position Statement of Indian Society of Anaesthesiologists (ISA Advisory and Position Statement of In

13. Luo M, Cao S, Wei L, Tang R, Hong S, Liu R,et al. Precautions for intubating patients with COVID-19. Anaesthesiology 2020;132:1616-8

14. Cook TM, El-Boghdadly K, McGuire B, McNarry AF, Patel A, Higgs A. Consensus guidelines for managing the airway in patients with COVID-19. Anesthesia 2020;75:785-99 